\title{
NONAN-2-OL ESTERS IN SORGHUM LEAF EPICUTICULAR WAX AND THEIR COLLECTION BY PREPARATIVE GAS CHROMATOGRAPHY
}

\author{
by \\ PENNY von WETTSTEIN-KNOWLES ${ }^{1.2}$, JØRN DALGAARD MIKKELSEN ${ }^{2.4}$ \\ and \\ JØRGEN ØGAARD MADSEN ${ }^{3}$ \\ ' Institute of Genetics, University of Copenhagen, \\ Øster Farimagsgade 2A, DK-1353 Copenhagen K \\ 'Department of Physiology, Carlsberg Laboratory, \\ Gamle Carlsberg Vej 10, DK-2500 Copenhagen Valby \\ ${ }^{3}$ Department of Organic Chemistry, \\ The Technical University of Denmark, DK-2800 Lyngby \\ ${ }^{4}$ Present address: Biokemisk Laboratorium, \\ De Danske Sukkerfabrikker, Langebrogade 1, DK-100I Copenhagen K
}

Keywords: Gramineae, pheromone, $\beta$-diketones, Locusta migratoria, mass spectrometry

Epicuticular wax from sorghum seedling leaves was isolated and analyzed by TLC and GC. Its composition was remarkably similar to that of waxes on many other Gramineae leaves with the exception that three alkan-2-ol esters (nonan-2-ol docosanoate, nonan-2-ol tetracosanoate, and nonan-2-ol hexacosanoate) were present. This was unexpected as such esters have hitherto only been reported in waxes of plants with the capability of synthesizing $\beta$-diketone lipids. The $C_{31}-C_{35}$ alkan-2-ol esters were separated from the $C_{38}-C_{56}$ alkan-1-ol esters by preparative $G C$. The column effluent was passed through a small Dexsil-300 trap maintained at $150{ }^{\circ} \mathrm{C}$, and the esters eluted therefrom with chloroform. This technique gave better than $90 \%$ recovery of a $\left[1-{ }^{14} \mathrm{C}\right]-\mathrm{C}_{32}$ ester.

\section{INTRODUCTION}

Disclosing the $\beta$-diketone (primarily, hentriacontan-14,16-dione and 25-hydroxyhentriacontan-14,16-dione) and esterified alkan-2-ol (primarily tridecan-2-ol and pentadecan-2-ol) biosynthetic pathways and their genetic control is our primary goal. As biological material we have used barley spikes of the eceriferum mu- tants which determine synthesis and deposition of the very long chain lipids on the external surface of epidermal cell walls. Since large amounts of material would spur attempts to isolate the enzymes involved, we have been looking for a plant which synthesizes one or more of the specified lipids on rapidly growing seedling leaves. Herein we identify nonan-2-ol

Abbreviations: $\mathrm{GC}=$ gas chromatography; $\mathrm{MS}=$ mass spectrometry; TLC = thin layer chromatography: TMS = trimethylsilyl. 
esters on primary sorghum (Funk G251) leaves and describe a technique for collecting them by preparative gas chomatography (GC).

\section{MATERIALS AND METHODS}

\subsection{Materials and chemical analyses}

Seeds of sorghum (Sorghum bicolor, Funk G251) were planted in vermiculite and germinated in the light at $23{ }^{\circ} \mathrm{C}(19)$. Ten or 12 days later the epicuticular wax was isolated from seedling leaves as described previously (34). The wax was separated into its component lipid classes by thin layer chromatography (TLC) using silica gel $\mathrm{H}$ (Merck) plates and developing them first with hexane and then with amylene stabilized chloroform or only with the second solvent. Lipid classes were visualized and recovered from the TLC plates as detailed earlier (42). The isolated lipid classes and/or their derivatives (42) were quantitatively analyzed via GC using Hewlett-Packard instrumentation and 3\% SP2100 columns (42). The retention times of the esters were compared with those of $\mathrm{C}_{24}, \mathrm{C}_{26}$ and $\mathrm{C}_{28}$ methyl esters and $\mathrm{C}_{26}, \mathrm{C}_{28}$ and $\mathrm{C}_{29}$ esters (dodecyl, tetradecyl and pentadecyl myristate) purchased from Analabs (North Haven, Conn., USA).

To ensure that after transmethylation (23) none of the moieties of the three unknown trapped esters (section 2.2) would be lost, a modified procedure for their isolation was developed. Five g of 100-200 mesh Florisil (KochLight Laboratories Ltd., Colnbrook Bucks, England) was added to a $1 \mathrm{~cm}$ (i.d.) glass column and rinsed with $50 \mathrm{ml}$ redistilled diethyl ether:hexane $(50: 50, \mathrm{v} / \mathrm{v})$ followed by $100 \mathrm{ml}$ hexane. Subsequent to transmethylation the ester moieties were extracted with $4 \times 3 \mathrm{ml}$ hexane, and loaded directly onto the column. Twenty $\mathrm{ml}$ hexane, $20 \mathrm{ml} \mathrm{5 \%}$ diethyl ether in hexane and $20 \mathrm{ml} 20 \%$ diethyl ether in hexane were passed through the column and collected separately. All the fatty acid methyl esters were eluted with $5 \%$ diethyl ether in hexane, and the alcohols with $20 \%$ diethyl ether in hexane. The fraction containing the alcohols was concentrated to about $1 \mathrm{ml}$ at $0^{\circ} \mathrm{C}$ under $\mathrm{N}_{2}$, transferred to a small vial and concentrated to $100 \mu \mathrm{l}$ at $0{ }^{\circ} \mathrm{C}$ before preparing trimethylsilyl (TMS) deriva- tives (25). Qualitative GC analyses were performed on a Packard 437 instrument with a single $2 \mathrm{~mm}$ (i.d.) $\times 1 \mathrm{~m}$ glass column containing $10 \%$ SE-30 on Chromosorb W,HP 80-100 mesh using conditions similar to those for the HewlettPackard instrument (42). The reported percent distributions of the trapped esters and their fatty acid moieties were estimated by triangulation.

GC-mass spectrometry (MS) analyses of the esters, the ester fatty acid methyl esters and alcohol-TMS derivatives were carried out (40). For confirmation of the alcohol moiety structure, TMS derivatives (40) of decan-1-ol, dodecan-1-ol and tetradecan-1-ol (from Applied Science, State College, PA, USA) and nonan-2ol were prepared and subjected to GC-MS. Nonan-2-ol was synthesized by reaction of heptylmagnesium bromide with acetaldehyde.

\subsection{Collection of esters by preparative GC}

The method previously employed in this laboratory of trapping the effluent of a GC column in Dexsil 300 at $-196^{\circ} \mathrm{C} \mathrm{(24)} \mathrm{gave} \mathrm{only} \mathrm{a} 5 \%$ yield with the unknown sorghum esters. This was unexpected as $96 \%$ of injected methyl $\left(1-{ }^{14} \mathrm{C}\right)$ palmitate was collectable (24). The poor trapping efficiency with the sorghum esters is presumably due to formation of an aerosol (17). To circumvent aerosol formation the eluate from the GC column must not be cooled below the melting point of the compound of interest. Since the $C_{32}$ ester hexadecyl palmitate has a melting point of $53-54{ }^{\circ} \mathrm{C}$, a minimum temperature of $100{ }^{\circ} \mathrm{C}$ was desired. Thus, the major arm from the column splitter of our radio-GC system (24) was disconnected after passing through the combustion oven reduced to $150^{\circ} \mathrm{C}$, and the $0.55 \mathrm{~cm}$ (i.d.) $\times 15.5 \mathrm{~cm}$ piece of quartz tubing containing copper oxide emptied and refilled with the

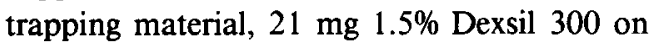
Chromosorb W AW, 60/80 mesh (Supelco, PA, USA). Esters trapped by the Dexsil were recovered by passing $3 \times 3 \mathrm{ml}$ of chloroform through the quartz tubing removed from the oven and cooled to room temperature. To test the efficiency of this technique a labelled $\mathrm{C}_{32}$ ester, namely $\left[1-{ }^{14} \mathrm{C}\right]$-docosanyl caprinate, was synthesized (28). Injection of known amounts of this ester followed by liquid scintillation counting of 


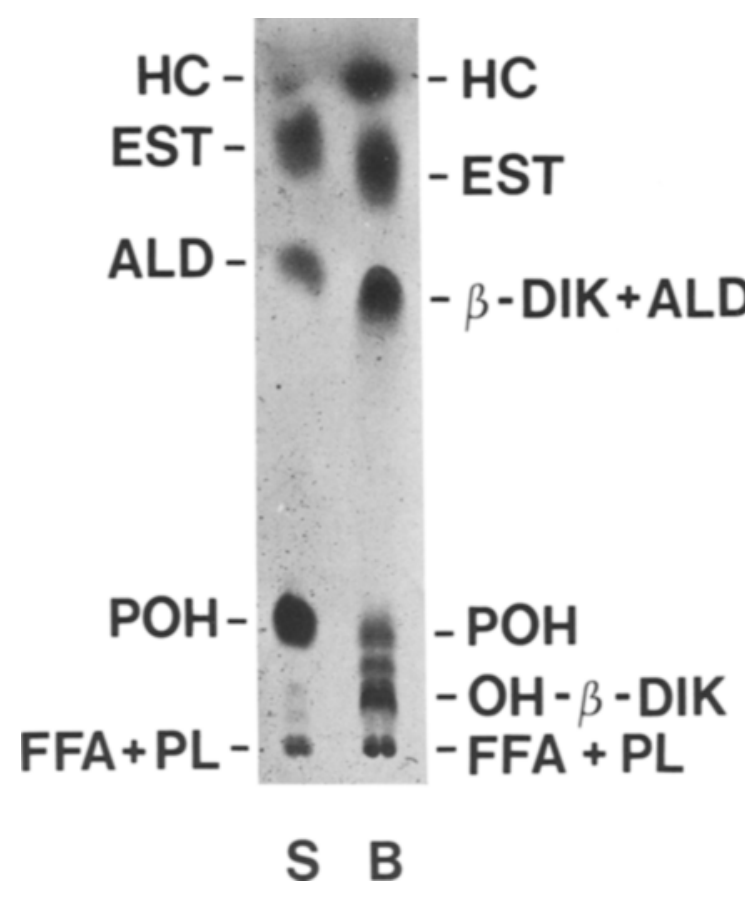

Figure 1. Compositions of the epicuticular waxes on seedling leaves of Funk G251 sorghum (S) and spikes of Bonus barley (B) as revealed by TLC.

The lipid classes were visualized by spraying with $55 \% \mathrm{H}_{2} \mathrm{SO}_{4}$ containing $0.6 \%$ (w/v) $\mathrm{K}_{2} \mathrm{Cr}_{2} \mathrm{O}_{7}$, followed by charring. $\mathrm{HC}=$ hydrocarbons, $\mathrm{EST}=$ esters, $\mathrm{ALD}$ $=$ aldehydes, $\mathrm{POH}=$ primary alcohols, $\mathrm{FFA}=$ free fatty acids, $P L=$ polar lipids, $\beta$-DIK $=\beta$-diketones, $\mathrm{OH}-\beta$-DIK $=$ hydroxy- $\beta$-diketones.

the chloroform extractable radioactivity gave an average trapping efficiency of $92 \%$ for four separate trials.

\section{RESULTS}

Figure 1 shows that the sorghum seedling leaf wax studied is composed principally of primary alcohols, esters and aldehydes in order of decreasing importance plus minor amounts of alkanes, free fatty acids and/or polar lipids plus several other unidentified compounds with $\mathrm{Rf}$ values between those of the primary alcohols and the free fatty acids. The slightly greater $R f$ of the sorghum than the barley esters suggests they have relatively more of the longest chain homologues. While p-hydroxybenzaldehyde is a prominent constituent of some sorghum waxes (17), it can not amount to more than a trace in the present wax as shown by co-TLC with an authentic standard. EBERT and RAMSTEINER (12) who also analyzed Funk G251 seedling wax report from MS of total wax a weight $\%$ distribution of primary alcohols $=65.9$, free fatty acids $=6.6$, aldehydes $=2.2$, esters $=5.7$ and unknowns $=19.6 \%$. From our results (Figure 1) we can not guess what the unknowns are, but we believe that the different growing conditions $(6$, 39 ) and analytical methods used have given rise to the discord between their results and ours for the identified lipid classes.

Preparative TLC was used to isolate the lipid classes which were then analyzed by GC. The normal alkanes amounting to at least $1 \%$ of the total wax were $\mathrm{C}_{25}=13.9, \mathrm{C}_{27}=14.4, \mathrm{C}_{29}=20.3$, $\mathrm{C}_{31}=39.9$ and $\mathrm{C}_{33}=2.6$. Table I presents the compositions of five additional wax fractions. The alcohol and free acid distributions are reasonably similar to those reported by EBERT and RAMSTEINER (12), whereas those of the other three lipid fractions are not, as Table I shows. We are unable to explain the discrepancy in the results, but again suggest that a difference in growing conditions may be partly responsible $(6,39)$. GC of the esters (Figure 2) gave the puzzling result that the presence of the three shortest components could not be accounted for by combining observed ester alcohol and acid moieties (Table I). This problem does not arise for the $\mathrm{C}_{38}$ to $\mathrm{C}_{56}$ esters, although the hypothesis of completely random esterification does not seem justifiable at first glance.

As a first step toward identifying the three unknowns, semilog plots of apparent carbon number vs retention time were constructed after isothermal GC with methyl and myristate ester standards. The sorghum unknowns eluted distinctly later than $\mathrm{C}_{28},{ }_{30}$ and ${ }_{32}$ methyl esters, and just before $\mathrm{C}_{30},{ }_{32}$ and ${ }_{34}$ myristate esters. Since the retention times of the sorghum unknowns relative to the myristate esters was reminescent to that of the alkan-2-ol vs alkan-1ol esters of barley (41), a coinjection of sorghum and barley spike esters was made. The three unknowns eluted together with the barley $C_{31},{ }_{33}$ and $_{35}$ alkan-2-ol esters. Separate injections followed by construction of semilog plots, how- 
Table I

Compositions of five lipid fractions from sorghum (Funk G251) seedling leaf wax (weight \%)

\begin{tabular}{|c|c|c|c|c|c|}
\hline $\begin{array}{l}\text { Number of } \\
\text { carbons }\end{array}$ & Aldehydes & Alcohols & $\begin{array}{l}\text { Free } \\
\text { acids }\end{array}$ & $\begin{array}{l}\text { Ester } \\
\text { alcohols }^{\mathrm{b}}\end{array}$ & $\begin{array}{l}\text { Ester } \\
\text { acids }\end{array}$ \\
\hline 16 & & & & & 2.9 \\
\hline 18 & & & & & 6.1 \\
\hline 20 & $(0.8)$ & & 1.2 & $3.1 \quad(7.5)$ & $49.7(19.3)$ \\
\hline 22 & $(1.2)$ & & 2.9 & $37.7(15.3)$ & $17.9(25.8)$ \\
\hline 24 & $(1.0)$ & & 7.6 & $5.0 \quad(5.1)$ & $17.0(17.9)$ \\
\hline 26 & $2.2 \quad(2.7)$ & 1.6 & 4.7 & $2.4 \quad(4.1)$ & $4.4 \quad(5.0)$ \\
\hline 28 & $14.4(35.6)$ & 23.4 & 39.3 & $22.0(37.1)$ & $1.1(12.0)$ \\
\hline 30 & $18.1(30.5)$ & 10.5 & 26.3 & $6.0(20.4)$ & $(13.4)$ \\
\hline 32 & $60.2(28.2)$ & 63.1 & 16.0 & $18.5(10.2)$ & $(9.5)$ \\
\hline 34 & 2.3 & & & & \\
\hline Other $^{\mathrm{c}}$ & 2.7 & 1.3 & 2.0 & 5.5 & 0.9 \\
\hline
\end{tabular}

ever, revealed that the sorghum unknowns eluted on the tailing sides of the barley peaks.

The three unknowns whose \% distribution in order of increasing retention time was $8.7,75.2$ and 16.0 , respectively, were next separated from the $\mathrm{C}_{38}$ to $\mathrm{C}_{56}$ esters by preparative $\mathrm{GC}$ as described in section 2.2. GC of the trapped material revealed only the three desired components in roughly $15.4,75.6$ and $9.0 \%$, respectively, which was considered adequate for further work. The trapped material was subjected to transesterification and the potential ester moieties prepared for GC-MS analyses as detailed in section 2.1. to avoid loss of short chain components. GC of one fraction revealed three peaks having the \% distribution of approximately 13.9, 73.7 and 12.4 which by GC-MS were identified as $\mathrm{C}_{22}, 24$ and ${ }_{26}$ methyl esters, respectively. This composition of the acid moieties is markedly different from that of the total ester fraction in which the 20 carbon chain lengths dominate (Table I), presumably explaining in part the apparent non-random esterification alluded to above. The only peak present in the gas chromatogram of the fraction which ought to contain alcohol TMS derivatives eluted at $113^{\circ} \mathrm{C}$. The presence in its mass spectrum of a base peak at $\mathrm{m} / \mathrm{z} 117$ and a smaller one (approx. 10\%) at m/z 201 are readily interpretable as $\alpha$-cleavage fragments of the TMS derivative of nonan-2-ol. The mass spectrum was identical to that of the known standard except that the latter had a trace peak at $\mathrm{m} / \mathrm{z} 215(\mathrm{M}-1)$. The identification of a single

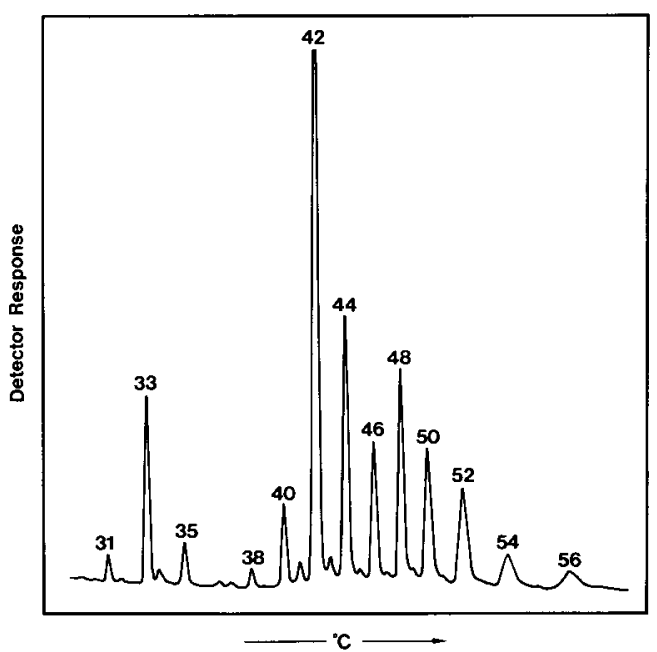

Figure 2. GLC trace of esters from seedling leaves of Funk G251 sorghum.

Total carbon numbers are given for the alkan-2-ol esters $\left(\mathrm{C}_{31}-\mathrm{C}_{35}\right)$ and alkan-1-ol esters $\left(\mathrm{C}_{38}-\mathrm{C}_{56}\right)$. 


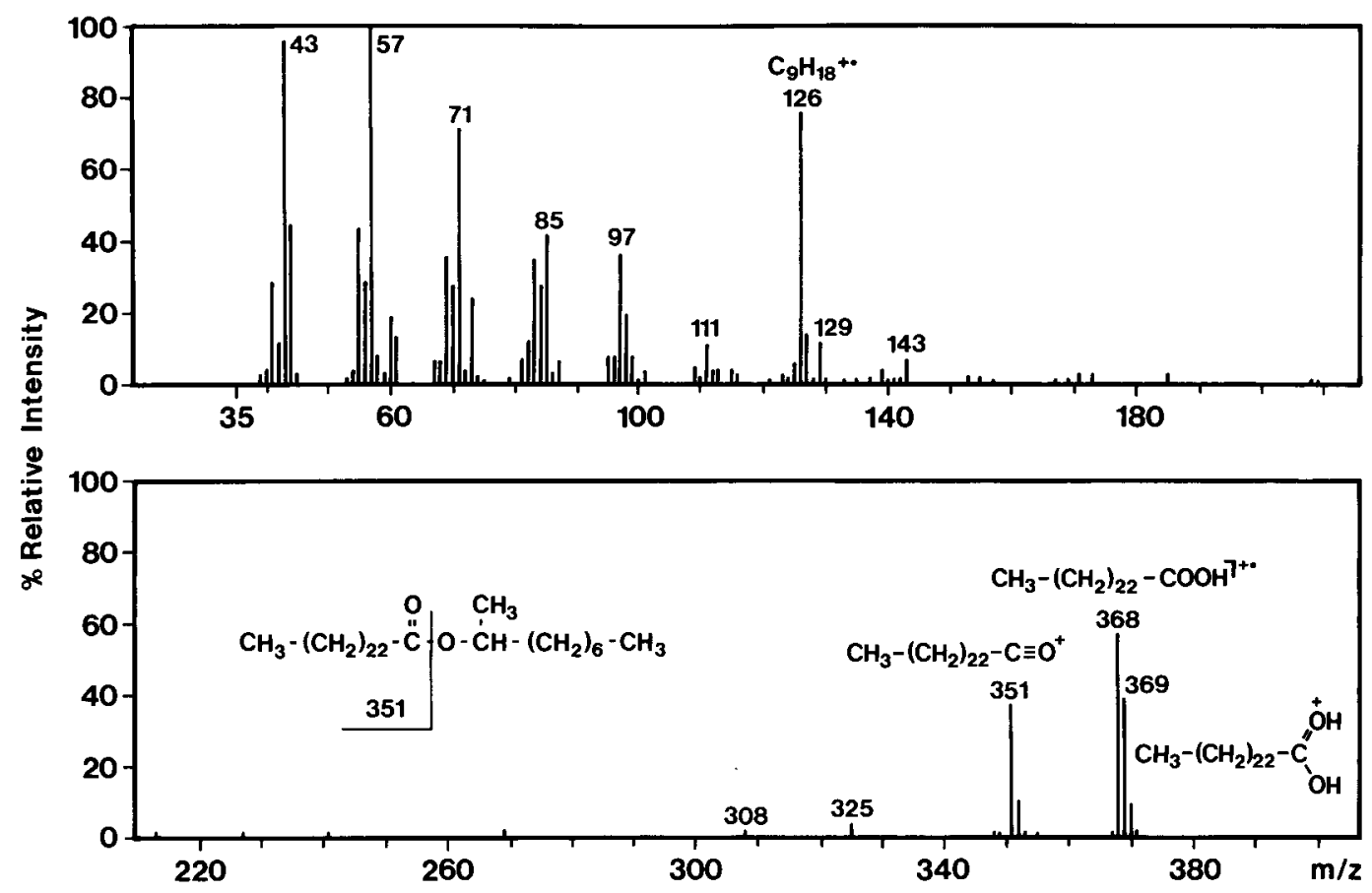

Figure 3. Mass spectrum of nonan-2-ol tetracosanoate.

alcohol combined with the similarity in \% distribution of the starting unknown esters and the derived acid moieties leads to the suggestion that the three unknowns in the sorghum esters are nonan-2-ol docosanoate, nonan-2-ol tetracosanoate and nonan-2-ol hexacosanoate.

To confirm these structural allocations, GCMS of the trapped esters was carried out. Figure 3 is a mass spectrum of the deduced $\mathrm{C}_{33}$ ester. The three peaks at $\mathrm{m} / \mathrm{z} 351,368$ and 369 are characteristic for the acid moiety fragments $\mathrm{RCO}^{+}, \mathrm{RCO}_{2} \mathrm{H}^{+}$and $\mathrm{RCO}_{2} \mathrm{H}_{2}^{+}$, respectively, where $\mathrm{R}=\mathrm{C}_{23} \mathrm{H}_{47}$; while the intense peak at $\mathrm{m} / \mathrm{z}$ 126 is attributable to the alcohol [R'-1] $]^{+}$fragment, where $\mathrm{R}^{\prime}=\mathrm{C}_{9} \mathrm{H}_{19}(1,41)$. Molecular ion peaks were neither expected nor detected. Absence of a peak at $\mathrm{m} / \mathrm{z} 154$ indicates that $\mathrm{C}_{11}$-2-ol isomers are not present in the $\mathrm{C}_{33}$ ester. Heptan2-ol isomers should give a $\left[\mathrm{R}^{\prime}-1\right]^{+}$fragment peak at $\mathrm{m} / \mathrm{z} 98$. Since peaks arising from the predicted $\mathrm{C}_{26}$ acid moiety, $\mathrm{RCO}^{+}, \mathrm{RCO}_{2} \mathrm{H}^{+}$and $\mathrm{RCO}_{2} \mathrm{H}_{2}{ }^{+}$at $\mathrm{m} / \mathrm{z} 379,396$ and 397, respectively, are not present, the existence of heptan-2-ol esters is considered unlikely.

\section{DISCUSSION}

Compositional analyses of cuticular waxes from a number of different types of sorghum including tropical to temperate varieties have been made $(2,4,8,9,12,43,44,45,46)$. The waxes have been collected from various individual organs or combinations thereof present in seedlings to mature plants using techniques ranging from those that remove only the surface lipids, that is, epicuticular waxes, to those that in addition extract internal lipids, for example, fatty acids. Thereafter, anywhere from one to five wax classes (including alkanes, esters, primary alcohols, free acids, aldehydes, and p-hydroxybenzaldehyde) have been studied with the level varying from relative amount determinations to complete chain length distribution anallyses of individual lipid classes or fractions. Even if allowances are made for the marked diversity of plants combined in the genus sorghum and the noted experimental differences, one is struck by the extraordinary range in wax composition reported. This includes the few cases where similarities might be expected. 
Compare the leaf blade analyses of the Italian varieties Alliance A and SD102 (8) with those of the American variety Redbine 60 and a bloomless mutant (43).

In the following we itemize what we consider the most interesting facets of this diversity. Firstly, that free acids can be predominant or major components of a plant wax $(4,8,9,45)$ is quite unusual. Likewise the presence of $\mathrm{p}$-hydroxybenzaldehyde is unexpected especially in such large amounts as in cv. 65D from Botswana $(44,46)$. Secondly, the thick, white waxy bloom present on parts of leaf blades and sheaths is not attributable to $\beta$-diketone lipids as it is in many other Gramineae $(7,26,36,42)$. In fact to our knowledge, this lipid class has not been reported in any sorghum wax. Thirdly, a number of the analyses specify chain lengths shorter or longer than characteristic for epicuticular waxes. For example, ester alcohols from Alliance $A$ and SD102 (8), free alcohols and alkanes in Redbine 60 and the bloomless mutant (43) and ester acids from 65D (45).

The presently investigated epicuticular wax from seedling leaves of Funk G251 lacks the special features noted above in points one and three. In fact the wax classes identified, their relative amounts and chain length compositions were all within the range of variation known from other Gramineae leaves such as barley (16, 35 ), corn (5), oats (31), wheat (32) and various grasses $(29,30,33)$. The only exception to this generalization was the identification of three nonan-2-ol esters. Hitherto, esterified alkan-2ols have only been identified in waxes from plants that synthesize $\beta$-diketones $(18,30,37)$. This is presumably a reflection of the close biosynthetic relationship between these two wax lipids $(25,38)$, the ease by which such short alcohols can be lost subsequent to ester hydrolysis and the failure of esterified alkan-2-ols, in contrast to $\beta$-diketone lipids, to contribute markedly to plant phenotype. Inhibition of $\beta$-diketone synthesis by genetic modification can lead to epicuticular waxes, however, in which esterified alkan-2-ols are present in the absence of $\beta$-diketones (37). Furthermore, alkan-2-ols may be located elsewhere than in epicuticular waxes which thus far is the only site of $\beta$-diketone lipids. $\mathrm{C}_{17}$ and $\mathrm{C}_{19}$-2-ols are present as monomers covalently attached to cutin and suberin polymers from corn, peas, lettuce and barley $(13,14)$. Of these four species only the latter is known to synthesize esterified alkan-2ols (41), but they are shorter, primarily $\mathrm{C}_{13}$ and $\mathrm{C}_{15}$, and are absent in epicuticular wax of the leaves which tissue was the source of the cutin polymer analyzed. In addition, both free and esterified alkan-2-ols ranging in length from 15 to 25 carbons are associated with but not covalently attached to the suberin layer of the periderm present in the underground storage organ of the parsnip (15).

Unlike many of the previous studies of sorghum waxes, the present one was not directed toward assigning the epicuticular wax or one of its constituents a specific function in, for example, drought resistance $(40,43)$ herbicide sensitivity $(11,12)$ or plant-insect interaction $(2,3,4$, $44,45,46)$. Our identification of nonan-2-ol esters, however, may be pertinent with respect to the recent reports $(3,45)$ that wax esters deter nymphs of Locusta migratoria from feeding on seedling leaves of cvs. CSH 1, IS 1082 and 65D. The ester fraction isolated from CSH1 and IS $1082(2,4)$ contained $\mathrm{C}_{40}-\mathrm{C}_{58}$ esters composed of $\mathrm{C}_{16}-\mathrm{C}_{30}$ alkan-1-ols and $\mathrm{C}_{14}-\mathrm{C}_{30}$ acids. The data, however, are inconsistent in failing to account for the esters by combining either randomly, as the authors point out, or non-randomly the reported moieties. Esters of 65D seedling leaves were almost completely separated by TLC into two fractions (45). This implies that the esters are of one type but fall into two markedly different groups of chain lengths and/or they are of two structurally different types, for example, in having alkan-1-ol vs alkan-2-ol moieties. WoODHEAD favors the former possibility and despite the fact that both isolated ester fractions were deterrent considers the shorter esters more effective. This deduction was based on an analysis of the acid moieties of one 65D ester fraction which revealed primarily $12-20$ carbons. Furthermore, nymphs were presented with $\mathrm{C}_{36}+\mathrm{C}_{38} \mathrm{vsC}_{46}+\mathrm{C}_{48}$ tetracosanyl esters. The former having $\mathrm{C}_{12}+\mathrm{C}_{14}$ acid moieties proved deterrent, while the latter having $C_{22}+C_{24}$ acid moieties was not. Unfortunately, the complementary distributions - of acid moieties from the other isolated 65D ester fraction, alcohol moieties from both fractions, 
and of the two ester fractions themselves needed to put WOODHEAD's speculation on a firm basis are not given. Confirmation of the structural nature behind the $65 \mathrm{D}$ ester deterrency is thus required. In the course of such investigations, we suggest that the potential existence of alkan-2-ol esters or derivatives of (40) be considered even though crs. 65D and Funk G25 I are not closely related. This proposal is based on the literature discussed above plus the known role of acetic and propionic acid esters of 3,7-dimethylpentadecan-2-ol as sex pheromones for two genera of pine sawflies $(20$, 22).

\section{ACKNOWLEDGEMENTS}

We are indebted to M. Petersen for outstanding technical assistance; to A.S. STEINHOLZ and N. RASMUSSEN for preparing the figures; and to E. EBERT (Agrochemical Division, CIBA-GEIGY Ltd., Basel, Switzerland) for asking us to examine FUNK G251 seedling leaves.

\section{REFERENCES}

1. ȦSEN, A.J., H.H. HOFSTETTER, B.T.R. IYENGAR \& R.T. HOLMAN: Identification and analysis of wax esters by mass spectrometry. Lipids 6, 502-507 (1971)

2. ATKIN, D.S.J. \& R.J. HamiLton: Surface of Sorghum bicolor. In: The Plant Cuticle. D.F. Cutler, K.L. Alvin \& C.E. Price, eds., Acad. Press, London. pp. 231-236 (1982a)

3. ATKIN, D.S.J. \& R.J. HAMiLTon: The effects of plant waxes on insects. J. Nat. Prod. 45, 694-696 (1982b)

4. ATKIN, D.S.J. \& R.J. HAMILTON: The changes with age in the epicuticular wax of Sorghum bicolor. J. Nat. Prod. 45,697-703 (1982c)

5. AVATo, P., J.D. MikKelsen \& P. von WetTSTEINKNOWLES: Effect of inhibitors on synthesis of fatty acyl chains present in waxes on developing maize leaves. Carlsberg Res. Commun. 45, 329-347 (1980)

6. Avato, P., J.D. Mikkelsen \& P. von WetTSteinKNOWLES: Synthesis of epicuticular primary alcohols and intracellular fatty acids by tissue slices from cer- $^{59}$ barley leaves. Carlsberg Res. Commun. 47, 377-390 (1982)

7. BAUM, B.R. \& A.P. TULLOCH: A survey of epicuticular waxes among genera of Triticeae. III. Syn- thesis and conclusion. Can. J. Bot. 60, 1761-1770 (1982)

8. Bianchi, G., P. Avato, P. Bertorelli \& G. MariANI: Epicuticular waxes of two sorgum varieties. Phytochemistry 17, 99-1001 (1978)

9. Bianchi, G., P. Avato \& G. Mariani: Composition of surface wax from sorghum grain. Cereal Chem. 56, 491-492 (1979)

10. BLuM, A.: Effect of the $B M$ gene on epicuticular wax deposition and the spectral characteristics of sorghum leaves. Sabrao J. 7, 45-52 (1975).

11. Ebert, E.: The role of waxes in the uptake of metolachlor into sorghum in relation to the protectant CGA 43089. Weed Res. 22, 305-311 (1982)

12. EBERT, E. \& K. RAMSTEINER: Influence of metolachlor and the metolachlor protectant CGA 43089 on the biosynthesis of epicuticular waxes on the primary leaves of Sorghum bicolor. Weed Res. in press

13. EsPelie, K.E., B.B. Dean \& P.E. Kolattukudy: Composition of lipid-derived polymers from different anatomical regions of several plant species. Plant Physiol. 64, 1089-1093 (1979)

14. EsPELIE, K.E. \& P.E. KOLATTUKUDY: Composition of the aliphatic components of 'suberin' from the bundle sheaths of Zea mays leaves. Plant Sci. Lett. 15, 225-230 (1979)

15. EsPelie, K.E., N.Z. SADEK \& P.E. Kolattukudy: Composition of suberin-associated waxes from the subterranean storage organs of seven plants. Planta 148, 468-476 (1980)

16. GIESE, B.N.: Effects of light and temperature on the composition of epicuticular wax of barley leaves. Phytochemistry 14, 921-929 (1975)

17. HARDY, R. \& J.N. KEARY: A trap for the collection of a series of fractions in the preparative scale gas chromatography of high molecular weight compounds. J. Chromatog. 17, 177-179 (1965)

18. HORN, D.H.S., Z.H. KRANZ \& J.A. LAMBERTON: The composition of Eucalyptus and some other leaf waxes. Aust. J. Chem. 17, 464-476 (1964)

19. HøJ, P.B. \& J.D. MrKKELSEN: Partial separation of individual enzyme activities of an ACP-dependent fatty acid synthetase from barley chloroplasts. Carlsberg Res. Commun. 47, 119-141 (1982)

20. JeWETt, D.M., F. MatSUMURA \& H.C.COPPEL: Sex pheromone specificity in the pine sawflies: interchange of acid moieties in an ester. Science 192, $51-53$ (1976)

21. LUNDQVist, U. \& P. VON WETTSTEIN-KNOWLES: Dominant mutations at Cer-yy change barley spike wax into leaf blade wax. Carlsberg Res. Commun. 47, 29-43 (1982)

22. Matsumura, F., A. Tal, H.C. Coppel \& $M$. IMAIDA: Chiral specificity of the sex pheromone 
of the red-headed pine sawfly, Neodiprion lecontei. J. Chem. Ecol. 5, 237-249 (1979)

23. MIKKeLSEN, J.D.: The effects of inhibitors on the biosynthesis of the long chain lipids with even carbon numbers in barley spike epicuticular wax. Carlsberg Res. Commun. 43, 15-35 (1978)

24. MiKKeLSEN, J.D.: Structure and biosynthesis of $\beta$-diketones in barley spike epicuticular wax. Carlsberg Res. Commun. 44,133-147 (1979)

25. MIKKELSEN. J.D.: Biosynthesis of esterified alkan2 -ols and $\beta$-diketones in barley spike epicuticular wax: synthesis of radioactive intermediates. Carlsberg Res. Commun. 49, $391-416$ (1984)

26. NetTing. A.G. \& P. von Wettstein-Knowles: The physico-chemical basis of leaf wettability in wheat. Planta 114, 289-309 (1973)

27. Simpson, D. \& P. von Wettstein-Knowles: Structure of epicuticular waxes on spikes and leaf sheaths of barley as revealed by a direct platinum replica technique. Carlsberg Res. Commun. 45, 465-481 (1980)

28. TONANI, R. \& G. BIANCHI: Mass spectrometry identification of long chain wax esters from maize. Maydica 21, 89-95 (1976)

29. Tulloch, A.P.: Composition of epicuticular waxes from 28 genera of Gramineae: differences between subfamilies. Can. J. Bot. 59, 1213-1221 (1981)

30. Tulloch. A.P.: Epicuticular waxes from Agropyron dasysiachyum. Agropyron riparium and Agropyron elongalum. Phytochemistry 22, 1605-1613 (1983)

31. TULLOCH, A.P. \& L.L. HOFfmaN: Leaf wax of oats. Lipids 8, 617-622 (1973a)

32. Tulloch. A.P. \& L.L. Hoffman: Leaf wax of Triticum aestivum. Phytochemistry 12, 22172223 (1973b)

33. TUlLoCH, A.P. \& L.L. Hoffman: Composition of epicuticular waxes of some grasses. Can. J. Bot. 55. 853-857 (1977)

34. Wettstein-KnOwles, P. von: The molecular phenotypes of the eceriferum mutants. In: Proc. 2nd. Int. Barley Genet. Symp. (1969). R.A. Nilan, ed., Washington State Univ. Press. Pullman. Wash., USA. pp. 146-193 (1972)

35. WetTSTEIN-KNOWLES, P. von: Gene mutation in barley inhibiting the production and use of $\mathrm{C}_{26}$ chains in epicuticular wax formation. FEBS Lett. 42, 187-191 (1974a)

36. WeTtSTEIN-KNOWLES, P von: Ultrastructure and origin of epicuticular wax iubes. J. Ultrastruct. Res. 46, 483-498 (1974b)

37. WetTSTEIN-KNOWLES. P. vON: Biosynthetic relationships between $\beta$-diketones and esterified alkan-2-ols deduced from epicuticular wax of barley mutants. Molec. gen. Genet. 144, 43-48 (1976)

38. WetTSTEIN-KNOWLES, P VON: Biosynthesis of epicuticular lipids as analyzed with the aid of gene mutations in barley. In: Biochemistry and metabolism of plant lipids. J.F.G.M. Wintermans \& P.J.C. Kuiper, eds., Elsevier/North Holland Biomedical Press. Amsterdam. pp. 69-78 (1982a)

39. WeTtSTEIN-KNOWLES, P. voN: Elongases and epicuticular wax biosynthesis. Physiol. Vég. 20, 797 809 (1982b)

40. WettStein-KnOWles. P. von \& J Ø. Madsen: 7-Oxopentadecan-2-ol esters - a new epicuticular wax lipid class. Carlsberg Res. Commun. 49, 57-67 (1984)

41. WetTSTEIN-KnOwLes. P. \& A.G. NetTing: Esterified alkan-1-ols and alkan-2-ols in barley epicuticular wax. Lipids II. 478-484 (1976)

42. WETTSTEIN-KNOWLES, P. VON \& B. SEGAARD: The cer-cqu region in barley: gene cluster or multifunctional gene. Carlsberg Res. Commun. 45. 125-141 (1980)

43. Wilkinson, R.E. \& D.G. Cummins: Epicuticular fatty acid, fatty alcohol, and alkane contents of bloom amd bloomless sorghum 'Redbine 60' leaves. Crop Sci. 21, 397-400 (1981)

44. WOODHEAD. S.: p-Hydroxybenzaldehyde in the surface wax of sorghum: its importance in seedling resistance to acridids. Entomol. Exp. \& Appl. 31, 296-302 (1982)

45. WOOdHFAD. S.: Surface chemistry of Sorghum bicolor and its importance in feeding by Locusta migratoria. Physiol. Entomol. 8, 345-352 (1983)

46. WoOdhiead, S., C. GalefFi \& G.B. Marini BetTOLO: A re-assessment of $p$-hydroxybenzaldehyde in Sorghum bicolor seedlings. Phytochemistry 23, 197-198 (1984) 